\title{
The Development of Probabilistic Time and Cost Data: Focus on field conditions and labor productivity
}

\author{
ChangTaek Hyun ${ }^{1}$, TaeHoon Hong ${ }^{2}$, SoungMin $\mathrm{Ji}^{3}$, JunHyeok $\mathrm{Yu}^{4}$, and SooBae $\mathrm{An}^{5}$
}

\begin{abstract}
Labor productivity is a significant factor associated with controlling time, cost, and quality. Many researchers have developed models to define methods of measuring the relationship between productivity and various parameters such as the size of working area, maximum working hours, and the crew composition. Most of the previous research has focused on estimating productivity; however, this research concentrates on estimating labor productivity and developing time and cost data for repetitive concrete pouring activity. In Korea, "Standard Estimating" only entails the average productivity data of the construction industry, and it is difficult to predict the time and cost spent on any particular project. As a result, errors occur in estimating duration and cost for individual activities or projects. To address these issues, this research sought to collect data, measure productivity, and develop time and cost data using labor productivity based on field conditions from the collected data. A probabilistic approach is also proposed to develop data. A case study is performed to validate this process using actual data collected from construction sites. It is possible that the result will be used as the EVMS baseline of cost management and schedule management.
\end{abstract}

Keywords: Labor productivity, probabilistic model, field condition, crew, time and cost data

\section{INTRODUCTION}

According to Sanvido [1], "Productivity is defined as the ratio of product output to input." Based on this definition, labor productivity can be determined using input and output data. Furthermore, "accuracy of estimating individual activity time and cost" can be achieved using reliable labor productivity data [2]. In Korea, "Standard Estimating" also deals with productivity data for different activities. However, since the concept stands for average productivity, it is difficult to predict the time and cost of any particular project.

Previous studies calculated time and cost using productivity in the early project phase and construction phase. Field conditions such as workable time and space were not considered. Thus, in a remodeling construction project with workable time and space constraints, errors in estimating arising from the use of average labor productivity can cause problems such as delayed building and going beyond the budget. Among the various construction-related activities, the scope of this study is limited to "concrete pouring," which allows productivity measurement with a focus on the critical path. Furthermore, since measuring the productivity of an activity generates a different result every time, a probabilistic approach that takes uncertainty into account has been introduced.
This paper presents a process of building the time and cost data of an activity considering productivity based on a probabilistic approach. The exhaustive model consists of three phases as shown in Figure 1. This study focuses on developing the time and cost data for an individual activity, which is Phase I .

FIGURE I

TIME AND COST ESTIMATING MODEL Time and Cost Estimating Model

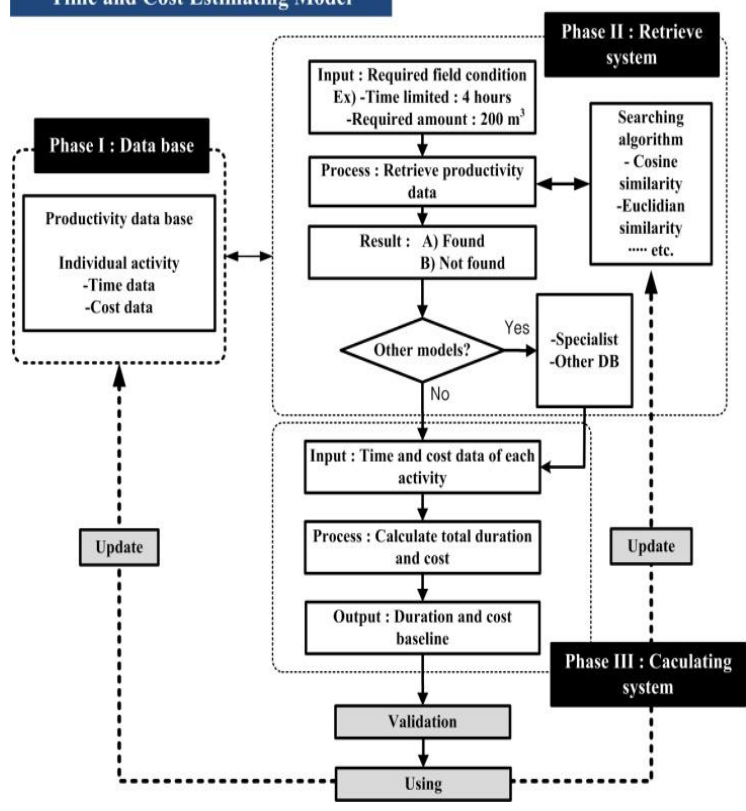

${ }^{1}$ Professor, University of Seoul, Seoulsiripdaero 163, Dongdaemun-gu, Seoul, South Korea, cthyun@uos.ac.kr

2 Assistant Professor, Yonsei University, A409, Engineering Hall 1, Yonsei University, Sinchon-dong, Seodaemun-gu, Seoul, South Korea, hong7 @yonsei.ac.kr ( ${ }^{*}$ Corresponding Author)

${ }^{3}$ Ph.D. Student, University of Seoul, Seoulsiripdaero 163, Dongdaemun-gu, Seoul, South Korea, noelji@hanmail.net

${ }^{4}$ M.S. Student, University of Seoul, Seoulsiripdaero 163, Dongdaemun-gu, Seoul, South Korea, junhappy0521@naver.com

${ }^{5}$ M.S. Student, University of Seoul, Seoulsiripdaero 163, Dongdaemun-gu, Seoul, South Korea, asb4713@nate.com 


\section{BACKGROUND OF RESEARCH}

In this study, efforts are made to manage and collect certain time and cost data. To provide a basic scheme for data collection and management, this study investigates the definition of productivity, factors influencing productivity, measurement and analysis of productivity, and the uses of productivity information.

\section{A. Productivity}

Productivity is also considered a significant measure of national economic strength and has been studied and tracked for years (Lester 1998). Estimators routinely used crew productivity during the process of bid preparation, monitored performance during construction, and employed a variety of analytical techniques tempered with judgments, experience, knowledge, and historical data (Portas and AbouRizk 1997).

Productivity is measured based on the production volume for the inputted resources and is categorized into labor, capital, and raw material productivity. In existing literature, productivity is normally considered to be the combination of input and output data. Therefore, it is quantified using the following method:

$$
\text { Productivity }=\frac{\text { Output }}{\text { Input }}
$$

where "input" is the inputted raw materials, power, tools, labor, cost, and time. "Output" is the volume or quantity of the products yielded.

\section{B. Factors for Estimating Productivity}

In the literature related to the analysis of factors influencing productivity in the construction industry, Hanna (1999) and Osama Moselhi (2005) together with their respective associates reported that change orders influenced the productivity of workers. Allmon and colleagues (2000) further described the characteristics of a project, technology, management, labor organization, real wage trend, and construction education as the factors that influence productivity.

Goodrum and Haas (2004) and Goodrum with his colleagues (2009) stated the effect of the development of equipment and material technologies on productivity. In addition, the experience of the project manager, the degree of perfection of the design, and the time reduction techniques were found to influence productivity factors (see Table 1).

Many existing studies that examined the factors influencing productivity have focused on design changes, technology changes, and management techniques. In this study, however, the factors influencing productivity are determined by analyzing the effects of daily work volume and work time on productivity.

\section{Productivity Measurement and Analysis}

Various data collection techniques are considered. In construction, labor productivity is specialized and related to operations and activities [3]. There are four methods used to measure labor productivity in construction: (1) productivity ratings; (2) five-minute rating; (3) continuous time study; and (4) work sampling. [3], [4].

TABLE I

PRODUCTIVITY FACTORS

\begin{tabular}{|c|c|}
\hline Researchers & Productivity Factors \\
\hline Hanna et al. (1999) & - Change orders \\
\hline Allmon et al. (2000) & $\begin{array}{l}\text { - Project uniqueness / - Technology } \\
\text { - Management / - Labor organization } \\
\text { - Real wage trends / - Training }\end{array}$ \\
\hline $\begin{array}{l}\text { Goodrum and Haas } \\
\text { (2004) }\end{array}$ & - Equipment technology \\
\hline $\begin{array}{l}\text { Osama Moselhi } \\
(2005)\end{array}$ & $\begin{array}{l}\text { - Change orders: intensity, timing in } \\
\text { relation to project duration, work type } \\
\text { - Type of impact, project phase } \\
\text { On-site management }\end{array}$ \\
\hline Cottrell (2006) & $\begin{array}{l}\text { - Design completeness } \\
\text { - Definition of a project vision statement } \\
\text { - Testing oversight } \\
\text { - Project manager experience and } \\
\text { - Dedication }\end{array}$ \\
\hline Hastak et al. (2008) & $\begin{array}{l}\text { - Management techniques } \\
\text { - Schedule reduction techniques } \\
\text { - CII best practices }\end{array}$ \\
\hline $\begin{array}{l}\text { Goodrum et al. } \\
(2009)\end{array}$ & $\begin{array}{l}\text { - Quantitative factors: } \\
\text { Material weight reduction, } \\
\text { strength, curability } \\
\text { - Qualitative factors: } \\
\text { Material installation, modularity }\end{array}$ \\
\hline
\end{tabular}

(1) Productivity ratings are used for measuring labor performance. It is impossible to record labor productivity every minute, and so a good sample design is needed. (2) The five-minute rating is based on observations made in a short period. However, if the observations are small, achieving statistical significance may be difficult [3]. In this method, the observations should be longer than five minutes. (3) Continuous time study is a good way to measure a specific action in a limited environment. At the start of the measurement process, the second hand of the watch is set to " 0 " and the time is recorded only when the composition of labor changes. Hence, the duration of each activity can be determined by comparing the preceding and following records after all measurements have been finished. (4) Work sampling is an analysis method used to quantify the composition ratio of each element comprising a certain type of work. The Association for the Advancement of Cost Engineering (AACE) states that "work sampling is a statistical technique that can be effectively used for analyzing the construction and maintenance work process" [4].

\section{Productivity Information}

Estimated productivity data is helpful in managing cost, schedule, and performance. Productivity data is used for the target productivity setting, performance measurement, cost and schedule planning, and integration of cost and schedule information [5].

(1) The accumulated productivity information can be used to set the target production for a specific activity. 
Specifically, the target production of an activity or project can be set through case studies and a heuristic approach based on past productivity information and the experience of experts. (2) Performance can be measured by comparing the work volumes at each milestone based on the defined target production. (3) The input cost and time for the target production for each activity can be predicted. Therefore, cost and schedule planning is possible. (4) When cost and schedule plans are established, it is possible to manage the cost and schedule in an integrated way for each activity.

\section{TIME AND COST DATA}

\section{A. Standard Estimating}

The standard estimation system that forms the basis of cost data used to calculate the expected price of public projects in Korea is based on the "Standard Estimating" guideline established by the Economic Planning Board (Budget Control Office) in 1968. It has been the only standard for estimating costs of public and private construction projects. This estimating standard numerically indicates the material quantity, labor quantity, and equipment usage time for unit work based on standard and universal work types and methods.

Although there have been many studies confirming the usefulness of "Standard Estimating" in construction works, the problem of low reliability in the existing cost data in actual projects has been raised repeatedly. In fact, studies analyzing the differences between the cost data used in estimation and the cost data in actual construction sites have recently been published. The problems of "Standard Estimating" presented in these studies are summarized in Table 2.

TABLE II

THE PROBLEMS OF "STANDARD ESTIMATING"

\begin{tabular}{|c|l|}
\hline Problems & \multicolumn{1}{c|}{ Details } \\
\hline $\begin{array}{c}\text { Establishment and } \\
\text { revision process }\end{array}$ & Lack of a specific, systematic process \\
\hline Labor & $\begin{array}{l}\text { There is a difference between the estimated } \\
\text { labor and the actual labor. The same Standard } \\
\text { Estimating is applied regardless of the field } \\
\text { conditions or engineering method. }\end{array}$ \\
\hline Cost & $\begin{array}{l}\text { The equipment cost is unrealistic compared to } \\
\text { other countries. There are no criteria for } \\
\text { calculating construction equipment costs } \\
\text { according to operating hours. The loss is } \\
\text { unrealistic and there is no clear basis of } \\
\text { calculation. Lack of wage characteristics by } \\
\text { region. Cost reduction factors according to } \\
\text { technology development are not reflected. }\end{array}$ \\
\hline Others & $\begin{array}{l}\text { There is a difference between the data on } \\
\text { standard and actual operation time (lack of } \\
\text { clear standard annual operation time) of } \\
\text { construction equipment. Other factors hinder } \\
\text { the application of new technologies and } \\
\text { methods. Complexity of calculation and cost } \\
\text { omission danger are probable. }\end{array}$ \\
\hline
\end{tabular}

Many of these problems are related to the accuracy of labor; however, there are not enough actual measurement data available to demonstrate how different labor estimation is from reality. Furthermore, the same estimation system is applied without considering the field conditions and engineering methods in detail. Therefore, it is necessary to examine the current "Standard Estimating" and to analyze overseas cases. If the estimation system can be improved in a constructive way by referring to overseas cases, the reliability of the system as well as the convenience of users will greatly improve.

\section{B. Productivity Estimating Concept}

To develop time and cost data, the price book of the USA, UK, and Japan is investigated, while the RS Means (Building Construction Cost Data) based on oneday productivity is used as the benchmark [6]. The RS Means offers construction cost information: daily productivity, input manpower, equipment, and cost data in many different situations. Thus, labor hours and bare cost are measured in this study among the many factors influencing productivity. Furthermore, a focus of this research is building the labor time and cost data for a day's work for each process.

Based on eight hours per day, the daily output has a negative correlation with labor, while bare cost has a negative correlation with labor number and labor cost. These correlations are illustrated in Figure 2.

This way, the productivity concept and the duration data can be established by calculating the input labor hours for output. Furthermore, cost data can be established by considering the input labor number and the labor cost. This process is identical to the process of establishing time and cost data of the RS Means, which is used in the U.S. [6].

FIGURE II

CAUSE AND EFFECT DIAGRAM ABOUT LABOR COST

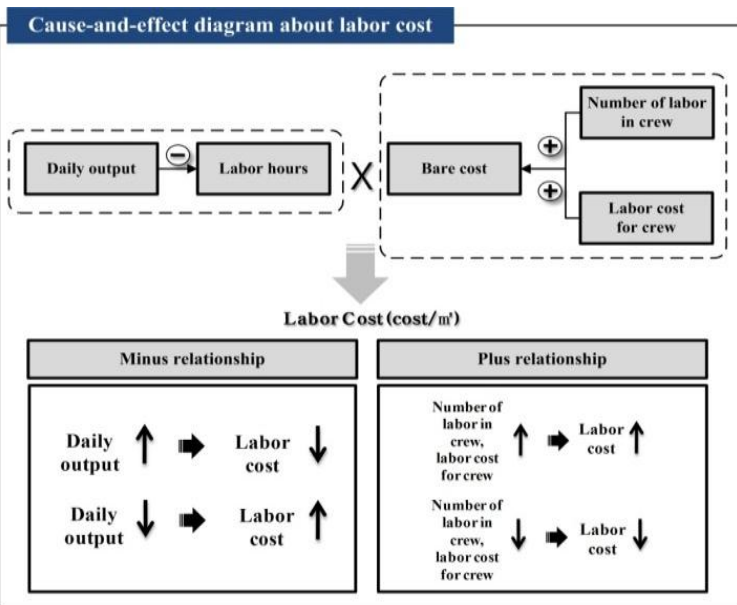

\section{Probabilistic Approach}

Many factors differentiate models, but when they are classified by the type of result, they can be divided into deterministic or probabilistic models. 
TABLE III

SITE INFORMATION TABLE

\begin{tabular}{|c|c|c|c|c|c|c|c|c|c|c|c|c|c|c|c|c|c|c|}
\hline & & & & & & & & Site Infor & rmatic & ion & & & & & & & & \\
\hline Field name & \multicolumn{3}{|c|}{ OO District } & \multicolumn{3}{|c|}{ Floor } & \multicolumn{3}{|c|}{ 4th Floors } & \multicolumn{4}{|c|}{ Observation date } & \multicolumn{2}{|r|}{2010.5 .26} & \multirow{2}{*}{ Weather } & \multirow{2}{*}{\multicolumn{2}{|c|}{ Clear }} \\
\hline Building & \multicolumn{3}{|c|}{307} & \multicolumn{3}{|c|}{ Number of households } & \multicolumn{3}{|c|}{3} & \multicolumn{4}{|c|}{ Observation start } & \multicolumn{2}{|r|}{ PM 1:30 } & & & \\
\hline Activity & \multicolumn{18}{|c|}{ Placing concrete } \\
\hline Start time & \multicolumn{2}{|c|}{$1: 30$} & \multicolumn{2}{|r|}{$2: 45$} & \multicolumn{2}{|c|}{$3: 40$} & $4: 33$ & \multicolumn{2}{|l|}{$4: 41$} & & $4: 53$ & \multicolumn{2}{|c|}{$5: 49$} & & $6: 25$ & $6: 40$ & \multicolumn{2}{|c|}{ Total time } \\
\hline End time & \multicolumn{2}{|c|}{$2: 45$} & \multicolumn{2}{|r|}{$3: 40$} & \multicolumn{2}{|c|}{$4: 33$} & $4: 41$ & \multicolumn{2}{|l|}{$4: 53$} & & $5: 49$ & \multicolumn{2}{|c|}{$6: 25$} & & $6: 40$ & $7: 05$ & & \\
\hline Work & \multicolumn{2}{|c|}{$\begin{array}{l}\text { Ready to } \\
\text { pump car }\end{array}$} & \multicolumn{2}{|c|}{$\begin{array}{l}\text { Households } \\
\text { Placement } \\
\text { (1) }\end{array}$} & \multicolumn{2}{|c|}{$\begin{array}{l}\text { Households } \\
\text { placement } \\
\text { (2) }\end{array}$} & $\begin{array}{c}\text { Core } \\
\text { placement }\end{array}$ & Rest tin & me & $\begin{array}{r}\mathrm{Hou} \\
\mathrm{Pla}\end{array}$ & $\begin{array}{l}\text { useholds } \\
\text { acement } \\
\text { (3) }\end{array}$ & Finish & ning & $\begin{array}{r}\text { D } \\
\text { dec }\end{array}$ & $\begin{array}{l}\text { Distributor } \\
\text { composition }\end{array}$ & Refinishi & ing & 35 \\
\hline Labor & 6 & & & 7 & 7 & & 7 & 7 & & & 7 & 7 & & & 7 & 7 & & \\
\hline & $\mathrm{Lal}$ & bor & & & & & terial & & & & Equip & oment & & & & Others & & \\
\hline $\begin{array}{c}\text { Labor } \mathrm{f} \\
\text { cement }\end{array}$ & $\begin{array}{l}\text { foreman } \\
\mathrm{t} \text { finisher }\end{array}$ & $\begin{array}{l}\text { (1), vibi } \\
\text { r (2), lab }\end{array}$ & $\begin{array}{l}\text { ratc } \\
\text { bor: }\end{array}$ & $\begin{array}{l}\text { or (2) } \\
\text { rs (2) }\end{array}$ & & Concrete & te $162 \mathrm{~m}^{3}$ & & & & ump car, & , Vibrator & & & & & & \\
\hline $\begin{array}{l}\text { Number } \\
\text { of R.M.C. }\end{array}$ & 1 & 2 & & 3 & 4 & 5 & 6 & 7 & 8 & & 9 & 10 & 11 & & 12 & 13 & 14 & $\cdots \cdots$ \\
\hline \begin{tabular}{|l|l} 
Start & 2 \\
\end{tabular} & $2: 44: 10$ & $2: 51: 01$ & & 14:51:01 & 15:00:09 & 15:07:32 1 & $15: 13: 43$ & 15:28:58 & $15: 37$ & $7: 301$ & $15: 43: 37$ & $15: 49: 54$ & 15:55: & 50 & $16: 01: 24$ & 16:06:51 & $16: 12: 32$ & $\ldots .$. \\
\hline End & $2: 50: 59$ & $2: 59: 4 C$ & & $14: 59: 49$ & 15:08:18 & $15: 14: 081$ & $15: 29: 09$ & 15:38:17 1 & $15: 44$ & $4: 021$ & $15: 50: 27$ & $15: 56: 101$ & 16:01: & :55 & $16: 07: 13$ & $16: 13: 03$ & $16: 18: 15$ & $\ldots .$. \\
\hline $\begin{array}{l}\text { The time } \\
\text { elapsed } \\
\text { (minute) }\end{array}$ & $6: 49$ & $6: 16$ & & $6: 23$ & 8:09 & $6: 36$ & $5: 25$ & $6: 10$ & $6: 3$ & & $6: 50$ & $6: 16$ & $6: 55$ & & $5: 49$ & $6: 12$ & $5: 43$ & $\ldots$. \\
\hline $\begin{array}{l}\text { Note } \\
\text { (Delay } \\
\text { time) }\end{array}$ & & $\begin{array}{l}14: 54: 2 \\
14: 56: 5\end{array}$ & & $\begin{array}{l}15: 04: 28- \\
15: 06: 53\end{array}$ & & & $\begin{array}{l}15: 14: 02 \\
15: 24: 11\end{array}$ & $\begin{array}{c}15: 30: 37- \\
15: 33: 16 \\
\ldots\end{array}$ & & & & & & & & & & $\ldots \ldots$ \\
\hline
\end{tabular}

The deterministic model derives a single result or a set of results as output data through defined input data sets. The probabilistic model derives various results (as output data through input data sets that are defined or have a probability distribution) and requires statistical interpretation for the results.

The probabilistic model is synonymous with the stochastic model, process, or system. The probabilistic approach uses mainly two methods: the second moment approach and the Monte-Carlo method. The former can determine the total cost and total duration through the mean, variance, standard deviation, and correlation coefficients between related variables. Since they are easily computed, it is easy to use spreadsheets or a handheld calculator. The Monte-Carlo method derives various results by simulating random events (random trials) for input data sets.

This study uses the second moment approach for the users' convenience and ease of acquiring the application program.

\section{PROCESS DEVELOPMENT}

\section{A. Data Collection}

As previously mentioned, concrete pouring activity is chosen as the target work type. To collect the productivity data of this activity, the target subject, work type, and construction site are selected. Among potential subjects (e.g., contractor, consultant, designer, subcontractor, and owner), the contractor is required to perform cost and schedule planning, and is therefore selected as the subject.
Since cooperation of the site is essential for collecting time and cost data based on the productivity of a reliable site, a contractor who is willing and cooperative in providing field information is chosen.

' $6 \mathrm{~m}^{3}$ ', the capacity of truck used to be a measure of pouring activity is shown in Figure 3. Productivity in the RMC (ready-mixed concrete) pouring truck unit is investigated. We observed 3 floors $\left(3^{\text {rd }}, 4^{\text {th }}\right.$, and $5^{\text {th }}$ floor $)$ and acquired 81 data sets through these processes (see Table 3).

FIGURE III

CONCEPT OF COLLECTING DATA

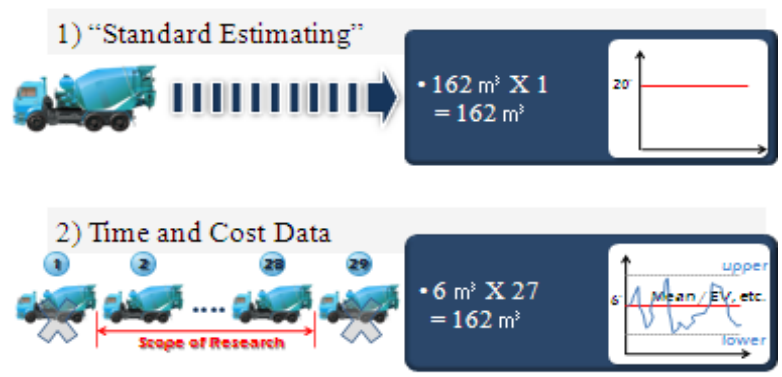

The working hour was measured by two observers who took turns every three hours. One recorded working hours from the time concrete falls to the time pouring is paused near the RCM; the other recorded working hours in the construction area. In this result, 4th RCM as shaded in Table 3, is recorded as 8 minutes, 9 seconds. 


\section{B. Data Analysis}

In order to apply the probabilistic concept, the distribution of the collected data needs to be identified. According to the "Central Limit Theorem," it is assumed that collected data followed "Normal Distribution." The second moment approach is later applied. The process can be summarized as follows:

FIGURE IV

DISTRIBUTION OF COLLECTING DATA

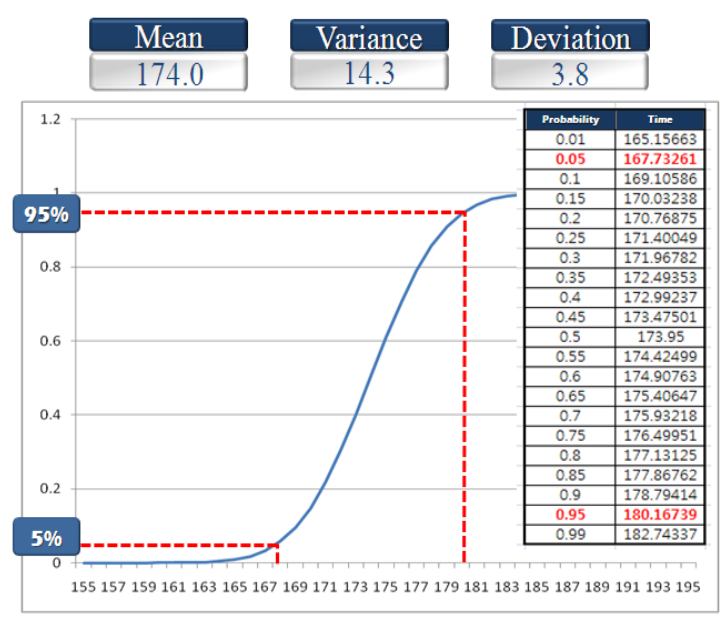

(1) Compute mean value, variance, standard deviation

(2) Compute correlation and covariance matrix

(3) Using the computed total mean and variance, normal assumptions, plot the probability distribution for total activity time

In this result, a seven-member crew's probabilistic productivity in concrete pouring is from 160 to 195 minutes per $162 \mathrm{~m} 3$ (see Figure 4). The probability of finishing in 167.7 minutes is $5 \%$, and the probability of finishing in 180.2 minutes is $95 \%$. The mean value is 174 minutes, and the expected value is 174.4 minutes.

\section{Productivity Data Translation Process}

Time and cost data from the estimated productivity (mean value or expected value) largely consists of (1) material information and (2) labor information [7].

(1) The material information is prepared using "Standard Estimating."

(2) The labor information is developed in the following sequence of considering the productivity calculated from the site [7].

a) Examine the crew responsible for the activity.

In the above example, the crew has four workers in Labor A (concrete labors) and three workers in Labor B (labors).

b) Determine the total labor hours of the crew based on eight hours per day.

Example:

Total Labor Hour (L.H.) $=7$ labors $\times 8 \mathrm{hr}=56 \mathrm{hr}$

c) Measure the area that can be worked by this crew for one day or the daily productivity of the crew.

The crew in this example can work $162 \mathrm{~m} 3$ per day. d) Determine the labor hours by substituting the total labor hours for daily productivity in the formula.

Example:

162/daily hour $=162 \mathrm{m3} /($ 7labor $\times 8$ hours $)$

$$
=2.89 \mathrm{~m} 3 / \mathrm{L} . \mathrm{H} \text {. }
$$

Get the reciprocal of the result of the above formula since the labor hours here are the input hours of the labor per unit area.

$$
\frac{1}{2.89 \mathrm{~m} 3 / \text { L.H. }}=0.35 \text { L.H. } / \mathrm{m} 3
$$

This means that 3.5 labor hours are required for crew "Conc-01" to work the construction unit of $10 \mathrm{~m} 3$.

e) Record the labor cost when the L.H. for the crew is input.

Example:

$$
\begin{gathered}
\cdot 4 \text { Concrete labors }=100,639 \mathrm{cost} / \text { day } \times \text { 4labor } \\
=402,556 \mathrm{cost} \cdot \text { labor } / \text { day } \\
\cdot 3 \text { labors }=67,909 \mathrm{cost} / \text { day } \times \text { 3labor } \\
=203,727 \mathrm{cost} \cdot \text { labor } / \text { day } \\
\text { - Total cost }=603,283
\end{gathered}
$$

f) Divide the cost of the crew by the L.H.

Example:

Cost Per L.H.= 606,283 cost $/$ day $\div$ 56L.H./day

$$
=10,826.5 \text { cost } / \text { L.H. }
$$

g) Determine the time and cost data by multiplying Labor hours by bare cost.

Example: Labor bare costs

$$
\begin{aligned}
& =10,826.5 \operatorname{cost} / \quad \text { L.H } \quad \times \quad 0.35 \quad \text { L.H./ } \quad \mathrm{m} \\
& =3,789.3 \cos \mathrm{t} / \mathrm{m} 3
\end{aligned}
$$

As a result of this process, the time and cost data of concrete pouring activity is developed (see Figure 5).

FIGURE V

TIME AND COST DATA

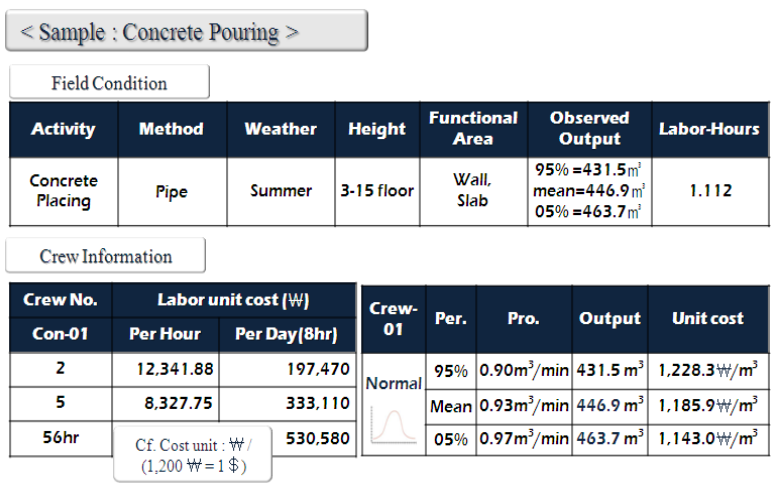




\section{VALIDATION}

The time and cost data can be established for the concrete pouring activity through the productivity data translation process.

In order to determine whether there are differences between this productivity data and "Standard Estimating," a t-test is performed. The t-test used to prove that the means of two groups are statistically different from each other [8]. In this study, the two groups are defined as follows:

Group A ( $\mu_{1}$ s the error rate between the productivity of the other construction site and the productivity of the time and cost data.

TABLE IV

THE T-TEST: TWO SAMPLES ASSUMING UNEQUAL VARIANCE

\begin{tabular}{ccccccccc}
\hline \multirow{2}{*}{ Category } & \multicolumn{9}{c}{ t-test } \\
\cline { 2 - 9 } & Mean & Variance & Observations & $\begin{array}{c}\text { Hypothesized } \\
\text { Mean D. }\end{array}$ & df & t Stat & $\begin{array}{c}\mathrm{P}(\mathrm{T}<=\mathrm{t}) \\
\text { one-tail }\end{array}$ & $\begin{array}{c}\mathrm{t} \text { Critical } \\
\text { one-tail }\end{array}$ \\
\hline GROUP A & 43.301 & 934.824 & 28 & 0 & 54 & -6.046 & 0.00000007 & 2.397 \\
GROUP B & 110.802 & 2554.978 & 28 & - & - & - & - & - \\
\hline
\end{tabular}

Group B ( $\mu_{2}$; the error rate between the productivity in the other construction site and the "Standard Estimating" results.

It is assumed that the mean error rate of Group A is less than that of Group B. Hence, the alternative hypothesis is as follows:

$$
\mathrm{H} 1:\left(\mu_{1}-\mu_{2}\right)<0
$$

As usual, the null hypothesis also follows:

$$
\text { H0: }\left(\mu_{1}-\mu_{2}\right)=0
$$

To identify the test statistic, the output between A and $\mathrm{B}$ is instructed. There is reason to believe that the population variances are not the same.

Consequently, this research uses the unequal-variances test statistic. The results are shown in Table 4.

The value of the test statistic is -6.05 . The one-tail $p$ value is near 0 . The $p$-value of the test is very small and the test statistic falls into the rejection region. As a result, there is evidence to infer that the data of Group A is more precise than of Group B.

Overall, the analyses by t-test indicate that the result of this productivity data has a significantly higher precision than the "Standard Estimating." However, a contractor should be aware that a significant precision exists among activities when field conditions are considered.

\section{CONCLUSIONS}

Many studies have suggested methods of collecting productivity data, measuring productivity, applications of productivity measures, and predicting productivity. However, development of processes and systems that can be easily used at the site has been insufficient. Thus, a specific algorithm that can be used with spreadsheets is required.

This study developed time and cost data for concrete pouring activity as the first phase of a research project. The main results of this study are as follows:

(1) To estimate duration and cost with productivity, the process of time and cost estimating model is presented.
(2) The time and cost data for complementing the existing "Standard Estimating" is developed by using a probabilistic approach and considering field conditions.

(3) The statistical test showed that the results are significant. In the future, we will collect data for other construction-related activities.

In addition, the result will be provided as the Earned Value Management System (EVMS) baseline for schedule and cost management. It will also be used to calculate more reliable duration and cost data for projects with time and space constraints.

Since this study only covered the concrete pouring activity, the scope should be expanded and the distributions should be modified in the future. More studies are also needed with regard to automation methods.

\section{ACKNOWLEDGEMENT}

This paper is supported by a grant (Grant No. 06 CIT A03) from the Research Policy and Infrastructure Development Program funded by the Ministry of Land, Transport and Maritime Affairs of the Korean government.

\section{REFERENCES}

[1] V.E. Sanvido, "Conceptual Construction Process Model”, 1988.

[2] A.N. Mohamed, "Knowledge based approach for productivity adjusted construction schedule", Expert systems with applications, vol. 21, no. 2, pp. 87-97, 2001.

[3] Md. Salim, L.E. Bernold, "Effects of Design-Integrated Process Planning on Productivity in rebar Placement", Journal of Construction Engineering and Management, vol. 120, no. 4, pp. 720-738, 1994.

[4] "Direct Labor Productivity Measurement - As Applied In Construction and Major Maintenance Projects", No. 22R-01, AACE International Recommended Practice, 2004

[5] K. Cho, T. Hong, C. Hyun, "Integrated schedule and cost model for repetitive construction process", Journal of Construction Engineering and Management, vol. 26, no. 2, pp. 78-88, 2010.

[6] RS Means, Building Construction Cost Data, 2010.

[7] Ministry of Land, Transport and Maritime Affairs of the Korean government, Development of estimating fair construction cost and building management system, 2010.

[8] K. Warrack, "Statistics for management and economics", Thomson Learning, Inc., 2003. 
[9] A.S. Hanna, J.S. Russell, T.W. Gotzion, E.V. Nordheim, "Impact of Change Orders on Labor Efficiency for Mechanical Construction", Journal of Construction Engineering and Management, vol. 125, no. 3, pp. 176-184, 1999.

[10] D.S. Cottrell, "Contractor Process Improvement for Enhancing Construction Productivity", Journal of Construction Engineering and Management, , vol. 132, no. 2, pp. 189-196, 2006.

[11] E. Allmon, C.T. Haas, J.D. Borcherding, P.M. Goodrum, "U.S. Construction Labor Productivity Trends, 1970-1998", Journal of Construction Engineering and Management, vol. 126, no. 2, pp. 97-104, 2000.

[12] M. Hastak, S. Gokhale, K. Goyani, T. Hong, B. Safi, "Analysis of Techniques Leading to Radical Reduction in Project Cycle Time", Journal of Construction Engineering and Management, vol. 134, no. 12, pp. 915-927, 2008.

[13] O. Moselhi, I. Assem, K. El-Rayes, "Change Orders Impact on Labor Productivity", Journal of Construction Engineering and Management, vol. 131, no. 3, pp. 354-359, 2005.

[14] P.M. Goodrum, D. Zhai, M.F. Yasin, "Relationship between Changes in Material Technology and Construction Productivity", Journal of Construction Engineering and Management, vol. 135, no.4, pp. 278-287, 2009.

[15] M. Loosemore, A.R.J. Dainty, H. Lingard, "Human resource management in construction project: strategic and operational approaches", London: Spon Press, 2003.

[16] Z. Abdullah, "The Effect of Human Resource Management Practices on Business Performance Among Private Companies in Malaysia", Business and Management, vol. 4, no. 6, pp. 65-72, 2009. 